\title{
O MARKETING 4.0 E A IMPORTÂNCIA DA COMUNICAÇÃO COM O NOVO CONSUMIDOR NAS REDES SOCIAIS
}

\section{ARTIGO ORIGINAL}

MEDEIROS, Ariany Corrêa ${ }^{1}$

BALDUÍNO, Maria Aparecida Canale ${ }^{2}$

MEDEIROS, Ariany Corrêa. BALDUÍNO, Maria Aparecida Canale. O marketing 4.0 e a importância da comunicação com o novo consumidor nas redes sociais. Revista Científica Multidisciplinar Núcleo do Conhecimento. Ano 04, Ed. 09, Vol. 01, pp. 160-175. Setembro de 2019. ISSN: 2448-0959, Link de acesso: https://www.nucleodoconhecimento.com.br/marketing/marketing-4-0

\section{RESUMO}

O artigo faz um estudo, ainda que inicial, sobre o Marketing 4.0 e sua ingerência sobre os processos de comunicação com o novo consumidor, enquanto meio digital utilizado nas redes sociais de mercado. Tal estudo, traz como intencionalidade de agregar informações, conhecimentos e a importância deste meio digital personalizado, como mediador da comunicação contemporânea de massa entre empresa e consumidor. Nessa apreensão, o artigo analisa a importância da comunicação no Marketing Digital 4.0 com os consumidores nas redes sociais da empresa Prime Residencial em Belém - Pará.

Palavras-Chave: Comunicação, marketing 4.0, mercado, consumidor, mídias digitais.

${ }^{1}$ Especialista em Gestão e Marketing Digital (UCDB), graduada em Comunicação Social - habilitação em Publicidade e Propaganda (FEAPA).

2 Professora Mestre da Universidade Católica Dom Bosco. Orientadora de Trabalho de Conclusão do Curso de pós-graduação Lato sensu da UCDB/Portal Educação. 


\section{INTRODUÇÃO}

Os estudos empreendidos pelo campo da Comunicação Social referentes aos meios digitais e sua aplicabilidade pelas redes sociais que medeiam a relação empresáriosconsumidores na contemporaneidade vêm ganhando expressão e possibilitando relações de proximidade de interesses e de satisfação entre sujeitos do mercado. $O$ tema deste artigo se relaciona aos conteúdos referentes ao Marketing Digital 4.0 e o processo de comunicação em meio à plataforma digital das redes sociais. Assim como, o objeto de estudo se justifica pela proximidade da pesquisadora em relação ao tema abordado - pelo fato de trabalhar na área como marketing digital em redes sociais da empresa a ser estudada -, o estudo e a análise proposta neste registro em se constituir em tema atual e em constante processo de transformação na comunicação.

Segundo Thomson (1995, p. 35), "De uma forma profunda e irreversível, o desenvolvimento da mídia transformou a natureza da produção e do intercâmbio simbólicos no mundo moderno". Então, o presente artigo, emite a preocupação da análise, do entendimento para responder às mudanças e adequações necessárias diante do processo contínuo de transformações nas relações comunicacionais mercadológicas na contemporaneidade.

O estudo em sua especificidade se voltará para analisar e apreender a importância e os resultados desta nova comunicação pautada nas relações entre consumidoresempresa oportunizadas pelas redes sociais da empresa Prime Residencial em BelémPará. Considerando-se que o novo consumidor a cada ano que passa, desenvolve novas formas de pensar, agir e se manifestar nas redes sociais, tornando-se sujeitos proativos nessa relação com os meios empresariais de serviços e produtos.

O problema de investigação se pautou na questão "Qual a importância da comunicação no marketing 4.0 junto ao novo consumidor em meio às redes sociais da empresa Prime Residencial em Belém-Pará?" como questão norteadora do processo de estudo e análise, ao considerar a importância da comunicação com o novo consumidor como elo relevante, pois, por meio da clareza e da experiência na 
troca de informações, esse consumidor cria vínculo com a empresa no meio digital, favorecendo futuramente a compra de produtos e/ou serviços disponibilizados na comunicação relacional. "É importante observar que os consumidores são, na verdade, indiferentes quanto ao canal [...] mas esperam uma experiência coerente e contínua ao longo de seu caminho até a compra." (KOTLER, 2017, p. 108). Nesse contexto de estratégias de comunicação e marketing mediadas pelas redes sociais, o estudo em questão apresenta a intencionalidade de analisar a importância da comunicação no Marketing Digital 4.0 com os consumidores nas redes sociais da empresa belenense Prime Residencial.

Assim sendo, a pesquisa foi realizada com base nas redes sociais da empresa de construção Prime Residencial, localizada na cidade de Belém, estado do Pará. O público-alvo para o estudo foram os consumidores que acessam e entram em contato com a empresa por meio das redes sociais, localizados no estado do Pará entre os municípios de Belém e Ananindeua. O público-alvo foi direcionado à homens e mulheres entre 25 e 65 anos que manifestaram interesses na compra de imóveis localizados nas classes C, D, E.

O aporte teórico-metodológico se subsidia nos estudos teóricos a respeito da sociedade contemporânea como sociedade da informação e da comunicação, e a partir dessa concepção societária, o estudo se direcionou para apreender e compreender a importância do Marketing 4.0, em particular sua trajetória, perpassando por todas as sua fases, desde o Marketing 1.0 ao estudado no referente artigo. O processo metodológico se pautou no estudo e a análise da importância da comunicação empresa-consumidor em meio às redes sociais empresa de construção Prime Residencial, mediante a aplicação de um instrumental de coleta de dados junto aos sujeitos que participam das redes sociais da empresa, na condição de consumidores ou futuros consumidores dos produtos e serviços desta empresa em questão. Para assegurar ou para dar entendimento à intencionalidade investigativa deste artigo, descrito na seção 2 referente aos caminhos metodológicos da pesquisa.

A proposta de estudo se constituiu em desafio e de relevância importância para a compreensão das relações entre sujeitos, consumidores e empresa, na apreensão de 
modos de pensar, interesses comuns, necessidades e satisfações, mediante a análise de respostas, posicionamentos e inferências de consumidores diante da aquisição e/ou desejos manifestos por produtos e serviços oferecidos pela empresa em questão.

\section{OS PROCESSOS DE COMUNICAÇÃO MEDIADOS PELAS REDES SOCIAIS NA CONTEMPORANEIDADE}

Com o avanço dos meios de comunicação, percebemos que os processos de comunicação cimentam as relações da convivência coletiva mediante o uso de linguagens que aproximam pessoas, coisas, serviços, produtos; pois, atribuem valor às pessoas, às coisas, sinalizam o lugar e a importância de ambos numa sociedade em que a cultura material tem destaque na sociedade contemporânea. "Um dos aspectos mais salientes da comunicação no mundo moderno é que ela acontece numa escala cada vez mais global.". (THOMPSON, 1995, p. 197) E por meio da evolução da mídia e dos meios de comunicação, podemos perceber que as relações de aproximação entre grupos são motivadas pela cultura e pelos processos comunicacionais ao qual estão inseridos na sociedade. Reúnem informação e comunicação que tendem a interconectar grupos com interesses - a priore distintos pela mediação desses interesses e objetivos a serem atingidos.

Segundo Caune (2014, p. 2) os interesses que movem a vida em sociedade se interceptam, pois: "Se os aparatos de comunicação são próprios de uma sociedade, as relações de comunicação envolvem os indivíduos pelo viés das relações interpessoais e pelos fenômenos de recepção dos meios de comunicação".

Na realidade, a era pós-industrial, que está por vir, apela a uma convergência de técnicas de informação e comunicação que, por certo, afetam os processos de produção e difusão do saber, os modos de pensamento, os momentos de entretenimento e, de forma mais geral, os comportamentos e as identidades culturais. (Idem)

Nesse processo interacional contemporâneo as mídias digitais assumem papéis relevantes na constituição da vida social quanto mundo mercadológico, que tem levado a sociedade atual a uma intensa inserção nos processos de informação e de comunicação. Os meios de comunicação e, especialmente as mídias digitais, 
tornaram-se sistemas de símbolos com linguagens próprias, passando a compor o novo universo socializador dos indivíduos e grupos, como processo de inclusão social, assim como, uma nova matriz da vida cultural da sociedade atual.

São inter relações marcadas pelos novos tempos que tendem a priorizar ações e relações no presente, ainda que, diante de um projeto e/ou de um "horizonte de expectativa" num futuro imediato pela centralidade da ação no tempo presente contínuo. (MARQUES, 2017, p. 15, apud KOJĖVE, 2002, p. 394) Ou seja, a vida societária passou a ser gerida pelo "aqui/agora", pelo imediato, impulsionados pelas contínuas transformações.

Esta percepção é trazida por Zygmunt Bauman quando afirma o rompimento das certezas dos tempos modernos ao reconhecer o colapso gradual e o rápido declínio da antiga ilusão moderna: da crença de que há um fim no caminho em que andamos, um télos alcançável da mudança histórica, um estado a ser atingindo amanhã, no próximo ano ou no próximo milênio. (MARQUES, 2017, p.17 apud BAUMAN, 1998). Referenciando a quebra das barreiras entre o século XX e o transitar para o século $\mathrm{XXI}$.

\subsection{TRAJETÓRIA DO MARKETING DESDE O TRADICIONAL AO DIGITAL}

Para que possamos nos aprofundar ainda mais nos processos de comunicação em meio as mídias sociais, é preciso entender as relações de consumo entre consumidorempresa com as quais a sociedade vem passando ao longo dos anos, e de como as tecnologias que vemos agora vêm convergindo e se adaptando ao novo indivíduo social contemporâneo por meio das práticas de marketing ao redor do mundo.

Para Kotler (2005, p. 13), "O Marketing é a ciência e a arte de explorar, criar e proporcionar valor para satisfazer as necessidades dos clientes de um mercado-alvo com rentabilidade. O marketing identifica necessidades e desejos insatisfeitos.". Ou seja, o Marketing não apenas envolve objetivo somente para vendas, mas engloba 
uma série de técnicas, práticas e estratégias a fim de agregar valor e importância às marcas ou produtos diante dos consumidores de um determinado público-alvo.

Hoje, com a internet, a conectividade trouxe grandes mudanças em meio à vida social do indivíduo consumidor em meio as redes sociais. Mas, para que possamos prosseguir com o entendimento sobre o Marketing 4.0, segue uma breve abordagem sobre as fases que o antecederam: Marketing 1.0, Marketing 2.0 e Marketing 3.0.

O Marketing 1.0 surgiu em meio a Revolução Industrial, onde o foco do mercado era o produto e sua venda padronizada em massa. O produto em si já era considerado suficiente para sua venda. Antes, o que era feito de forma artesanal e baixa escala, agora era feito industrialmente em alta escala e preços acessíveis. Foi o período em que as práticas de consumo e do consumidor começavam a nascer.

O segundo, o Marketing 2.0, nasceu juntamente com a Era da Informação. As marcas e empresas utilizavam canais eletrônicos, como a televisão, para chamar a atenção do consumidor para o seu produto. Neste período, o consumidor já dispunha de mais variedade para a compra e definir, por fim, sua final preferência. Era necessário que os profissionais de marketing desenvolvessem diferenciais em estratégias de vendas para seus produtos e serviços, o surgimento dos 4Ps do Marketing (Preço, Praça, Produto e Promoção).

Com a chegada do século XXI, o Marketing 3.0 vem com uma nova proposta, no qual o foco é baseado, não mais somente na venda em si, mas no lado mais humano do consumidor, como indivíduo social que tem anseios, valores e objetivos de vida; e que a cada compra deseja se satisfazer como humano. "Do ponto de vista da comunicação de marketing, os consumidores não são alvos passivos; estão se tornando mídias ativas de comunicação.". (KOTLER, 2017, p. 28). Ou seja, com os avanços da conectividade no mundo digital, os consumidores se tornaram clientes cada vez mais conectados em redes horizontais de comunidades. Estas consideradas como os novos segmentos de mercado. 
Esta nova segmentação de mercado e inter relações sociais heterogêneas entre consumidor-empresa, agora por meio da combinação de interação on-line e off-line é o que caracteriza o Marketing 4.0. Atualmente, a fase na qual é possível visualizar maior integração entre os canais de marketing (on-line e off-line) e o grande consumo de conteúdo digital no mundo (Marketing de Conteúdo) e interações sociais.

\subsection{CONCEITO DE MARKETING 4.0 E AS RELAÇÕES NAS MÍDIAS SOCIAIS}

Rez (2018, on-line) diz que: O Marketing 4.0 é uma abordagem de marketing que leva em conta os sentimentos humanos, as transformações sociais e as revoluções de interação na rede. Ou seja, essa nova fase do marketing traz consigo o poder da inclusão digital e interação

por meio de tecnologias digitais e tradicionais. Kotler (2017, p. 63) afirma que "na economia digital, a interação digital sozinha não é suficiente. Na verdade, em um consumo cada vez mais conectado, o toque off-line representa uma forte diferenciação". E essa inclusão entre os novos indivíduos sociais - como consumidores ativos e heterogêneos - permite que os processos de inter relação por meio dos canais de marketing fortaleçam cada vez mais o engajamento com o consumidor contemporâneo. Este mais ativo e conectado em meio a rede digital e seus diversos canais.

Em nível micro, as pessoas estão adotando a inclusão social. Ser inclusivo não significa ser semelhante. Significa viver em harmonia apesar das diferenças. No mundo on-line, as mídias sociais redefiniram o modo como as pessoas interagem entre si, permitindo que desenvolvam relacionamentos sem barreiras e demográficas. (KOTLER, 2017, p. 24)

A conectividade muito contribuiu para esta nova caracterização do novo indivíduo contemporâneo e em como se impõe de forma generalizada as relações sociais. Consumidores estão cada vez mais "próximos" uns dos outros no sentido social. Segundo Thompson (1995, 
p. 249), são indivíduos com "um sentido de pertença à comunidade", em pertencer a uma mesma comunidade digital vivenciada por indivíduos heterogêneos, ativos e que gostam de compartilhar suas ideias, conselhos e experiências uns com os outros, além de as copilarem em diversos acervos de avaliações; principalmente quando se dá por meio das mídias sociais referentes à empresas e marcas. A esse respeito, Kotler (2017, p. 28) afirma que, "Juntos, pintam o próprio quadro de empresas e marcas, que muitas vezes é bem diferente da imagem que as empresas e marcas pretendem projetar. A internet, sobretudo a mídia social, facilitou essa grande mudança fornecendo plataformas e ferramentas.".

Neste contexto, Setton (2018) diz que:

As maneiras pelas quais interagimos e nos adaptamos ao mundo, as maneiras pelas quais orientamos nossas práticas cotidianas, as formas de perceber 0 outro e a nós mesmos mudaram a partir da presença constante das mídias em nossas vidas. [...] Informações, apelos de consumo, modelos e estilos de vida veiculados pelas mensagens de uma indústria da cultura que compõem o imaginário e a vida prática de todos. Assim, no momento de uma compra ou no momento da escolha de uma revista em quadrinhos podemos estar sendo influenciados pela publicidade ou pelos nossos amigos ou familiares. (SETTON, 2018, p. 23)

Então, a rápida difusão de conteúdos, informações e publicidades por meio da plataforma digital, principalmente nas mídias sociais, molda os processos de formação sócio- cultural do novo consumidor com outros consumidores - dentro das comunidades - e sua relação com as empresas/marcas. Quintanilha (2012, on-line) exemplifica que, as mídias sociais são espaços de interação entre usuários. São considerados exemplos de mídias sociais: blogs, microblogs (Twitter), redes sociais (Facebook), fóruns, e-groups, instant messengers, wikis, sites de compartilhamento de conteúdo multimídia (YouTube, Flickr, SlideShare, Vimeo). Esses canais propiciam o diálogo e o compartilhamento de ideias e informações trazendo oportunidades voltadas para grandes e pequenas empresas assim como para indivíduosconsumidores que queiram expor suas ideias e opiniões no percurso desde a recepção da mensagem até o pós-compra de um produto ou serviço. Sendo assim, 
as mídias sociais são consideradas um meio propício para divulgação e propagação de ideias e conceitos da marca/empresa e dos consumidores.

\subsection{INTERAÇÃO CONSUMIDOR-EMPRESA}

Como já foi visto antes, o consumidor contemporâneo inserido nesta gama de canais comunicacionais e sociais, vem evoluindo desde o Marketing 3.0; o consumidor humano com sentimentos, valores e morais aos quais as empresas vêm adaptando suas estratégias de relacionamento de marketing em seus canais, de mídias sociais e digitais, para que o engajamento com esse indivíduo-consumidor seja maior (Marketing 4.0). Mas, para isso, é necessário que as empresas percebam as mudanças de recebimento da comunicação.

No passado, os consumidores eram facilmente influenciados por campanhas de marketing. [...] Entretanto, pesquisas recentes em diferentes setores mostram que a maioria dos consumidores acredita mais no fator social (amigos, família, seguidores do Facebook e do Twitter) do que nas comunicações de marketing. A maioria pede conselhos a estranhos nas mídias sociais e confia neles mais que nas opiniões advindas da publicidade e de especialistas. (KOTLER, 2017, p. 27)

Sendo assim, as empresas devem considerar revelar seus verdadeiros valores, ser o mais transparente possível para que, assim, o conceito de confiança do consumidor possa ser a favor da marca. Kotler (2017, p. 27) diz que "Os consumidores deveriam ser considerados colegas e amigos da marca." Pois, visto que, nessa nova era digital, as empresas não possuem mais controle sobre as recepções das comunicações de marketing, o único modo de se conseguir a confiança do consumidor é pela transparência no mundo digital.

Um outro ponto chave está relacionado ao modo que a conectividade afeta concorrência e consumidores. Hoje em dia, é considerado fundamental que exista colaboração entre concorrentes e a cocriação junto aos consumidores para uma engajamento amplo e completo de interação, assim como Kotler (2017, p. 35) afirma quando diz que "Os clientes não são mais receptores passivos de ações de segmentação, direcionamento e posicionamento de uma empresa.". O autor acredita 
que, com a dinâmica da conectividade, é quase impossível que uma empresa sobreviva sozinha no mercado. As empresas devem ter a percepção que no mundo globalizado de hoje, em meio a tantos canais de interação digitais e socais com concorrentes e consumidores, devem aderir a ideia de que precisam colaborar com outras empresas e até mesmo clientes.

\section{CAMINHOS METODOLÓGICOS DA PESQUISA}

Nosso foco de investigação foi direcionado pela hipótese de trabalho, enquanto questão norteadora: "Qual a importância da comunicação no marketing $4.0 \mathrm{com}$ o novo consumidor em meio às redes sociais da empresa Prime Residencial em BelémPará?", então, baseada na relevância dos processos de comunicação na efetivação das relações empresa- consumidores, por considerar que o uso do marketing nas redes sociais de clientes ou possíveis clientes desta empresa, tem possibilitado a clareza de informações, a troca de comunicações e o estabelecimento de vínculos dos consumidores com a empresa no meio digital. Um processo de interações entre sujeitos, com a perspectiva de torná-los num futuro próximo, compradores de produtos e/ou serviços.

A eleição do uso do Marketing 4.0 nas redes sociais, está diretamente associada aos conteúdos ministrados no Curso de Pós-graduação Lato Sensu em Gestão e Marketing Digital, assim como pelos interesses da pesquisadora, por atuar profissionalmente no campo das redes sociais, como ferramenta dos processos de comunicação que promove a relação e o diálogo entre consumidores e a empresa em que trabalha.

Com essa preocupação, o artigo como documento final traz o objetivo geral de: analisar, apreender a importância e os resultados da comunicação no Marketing 4.0 com os consumidores nas redes sociais da empresa belenense Prime Residencial; e de maneira especifica, objetiva:

- Conceituar Marketing Tradicional e Marketing 4.0; 
- Identificar o tipo de comunicação utilizada pelo Marketing Tradicional e Marketing Digital 4.0;

- Analisar o lugar do novo consumidor em meio às redes sociais;

- Avaliar o padrão de satisfação do novo consumidor com base no modelo de comunicação do marketing digital nas redes sociais da empresa Prime Residencial.

\subsection{O LÓCUS DA PESQUISA}

A pesquisa foi realizada com base nas redes sociais da empresa de construção Prime Residencial, localizada na cidade de Belém, estado do Pará.

Fundada há 12 anos, a empresa de construção e engenharia Prime Residencial tem como trajetória de atuação a construção de obras - condomínios de apartamentos e casas - para seguimentos de consumidores de classes C, D e E; preços acessíveis e com uma bagagem de mais de 1.780 unidades residenciais entregues.

\subsection{SUJEITOS DA PESQUISA}

Consumidores que acessaram e entraram em contato com a empresa por meio das redes sociais; localizados no estado do Pará entre os municípios de Belém e Ananindeua. $O$ público-alvo foi direcionado a homens e mulheres entre 25 e 65 anos que tinham interesse na compra de imóveis para as classes C, D, E.

Para efeito do processo de análise, foram escolhidos 20 consumidores ou pretensos consumidores de forma aleatória, que forneceram subsídios para o processo de estudo e análise.

\subsection{ESTRATÉGIAS INVESTIGATIVAS}

As estratégias utilizadas apresentam-se subdivididas em quatro eixos para a efetivação deste estudo:

A. Levantamento de referências sobre a temática: livros, artigos, blogs, sites; 
B. Aplicação de instrumental de coleta de dados junto aos consumidores;

C. Estudo, análise e interpretação de dados;

D. Construção do documento final.

\section{ANÁLISE E RESULTADOS}

Com o advento das tecnologias de informação e comunicação no contexto social contemporâneo, as redes sociais tornaram-se instrumentais de interlocução de pessoas e grupos da sociedade atual. A utilização das redes sociais como estratégia de marketing empresarial na internet é utilizada pelas empresas com vista à divulgação de produtos, serviços e também ao estabelecimento mais direto e transparente de comunicação, a fim de engajar um número maior de possíveis consumidores, proporcionada pela relação quase imediata que o Marketing 4.0 proporciona entre empresas e clientes no âmbito digital.

Com o objetivo principal de analisar e apreender a importância e os resultados da comunicação no Marketing 4.0 com os consumidores nas redes sociais da empresa belenense Prime Residencial, o processo de análise centrou-se baseado nas respostas dos usuários das redes sociais (Facebook e Instagram) vinculados ao perfil da Prime Residencial. A coleta de dados e/ou respostas foi pautada na aplicação de formulário com a intencionalidade de: analisar o lugar do novo consumidor em meio às redes sociais e avaliar o padrão de satisfação do novo consumidor com base no modelo de comunicação do marketing digital nas redes sociais da empresa.

Informamos que embora tenhamos indicado nos caminhos metodológicos a aplicação deste instrumental junto a 20 participantes de forma aleatória; obtivemos a devolução de apenas 10 formulários respondidos. Acreditamos que por conta do período de férias escolares e trabalhista em nossa região mais e o curto tempo para fechamento da pesquisa, consideramos tais registros para esse estudo inicial para conclusão deste artigo. 
Foi elaborado um formulário como instrumental para que a coleta de dados fosse baseada principalmente com foco na satisfação dos usuários quanto às estratégias de comunicação de marketing adotadas pela empresa Prime Residencial no âmbito digital (redes sociais da empresa); se eram satisfatórias e cumpriam com seu papel de plataformas de interação comunicacional. Foram nove questões, sendo que as oito primeiras foram questões fechadas, para uma análise mais quantitativa, e a última, abrimos espaço para uma questão aberta. Esse tipo de questão não sugere ou induz a qualquer tipo de resposta e foram dadas pelas palavras do próprio participante, para que pudesse se expressar com mais propriedade e a análise fosse feita de maneira qualitativa. As questões foram colocadas da seguinte maneira: 1) nome; 2) sexo; 3) faixa etária; 4) há quanto tempo o usuário é nosso cliente ou participante das redes sociais da empresa?; 5) como encontrou a empresa (meios on-line ou off-line)?; 6) em relação às redes sociais da empresa, você considera o serviço satisfatório?; 7) quanto ao atendimento, retorno de informações, classifique de 1 (péssimo) a 5 (excelente); 8 ) pelas informações e serviços fornecidos, você indicaria os produtos da Prime Residencial; e por último, a questão aberta: 9) na sua opinião, o que poderia mudar (ou agregar) para que o serviço e a comunicação disponibilizados fossem melhores nas redes sociais da empresa?.

Com base nos dados registrados por meio do formulário aplicado entre os usuários que seguem os perfis e entram em contato com a empresa de construção por meio das redes sociais, apresentamos suas análises com base nas questões indicadas pelo instrumental.

Procuramos neste estudo e análise o agrupamento das seções que se complementam para que seu entendimento fosse colocado de maneira clara e coerente. Nesse sentido, o processo de análise atendeu ao problema investigativo, seu objetivo geral e específicos como norteadores deste artigo.

\subsection{SEXO E FAIXA ETÁRIA (IDADE) DOS PARTICIPANTES}

Quanto ao sexo dos participantes, podemos demonstrar a seguinte configuração segundo o gráfico abaixo: 
Gráfico 1 - Questão 2 do formulário: Sexo

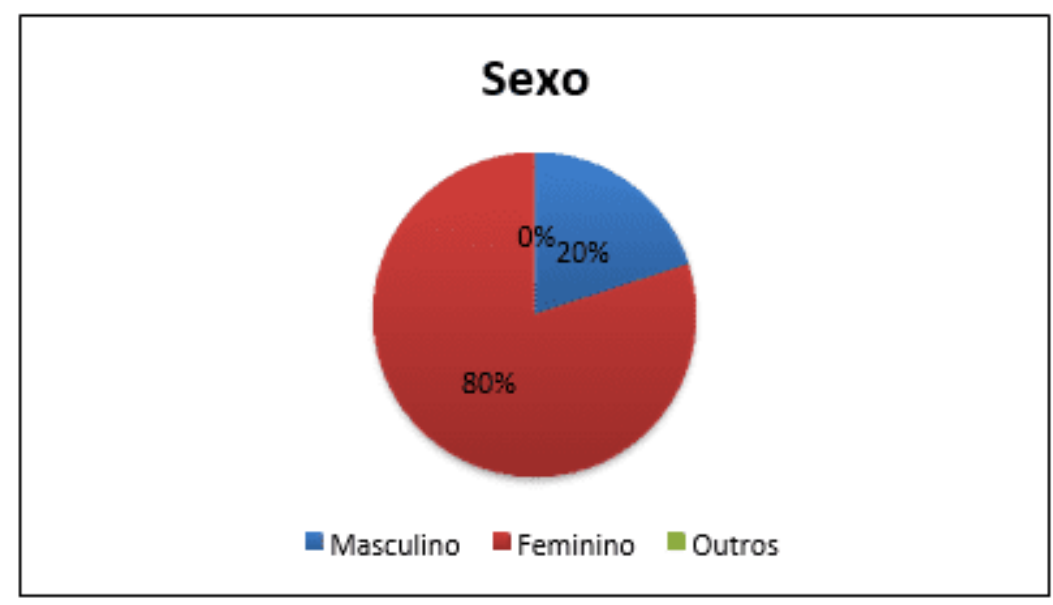

Fonte: Própria autora (2018)

Aqui, temos a representação gráfica relacionada ao sexo dos participantes do formulário. Nesse ponto, vimos o destaque do sexo feminino, com $80 \%$ do total de participação na pesquisa. Uma apreensão também referida por Philip Kotler (2017):

A influência que as mulheres exercem sobre outras pessoas é definida pela atividade que realizam. [...] Em termos simples, o mundo das mulheres gira em torno na família e do trabalho. [...] as mulheres são compradoras holísticas. [...] Elas tendem a avaliar tudo - benefícios funcionais, benefícios emocionais, preço e demais características antes de definir o verdadeiro valor dos produtos e serviços. (KOTLER, 2017, p. 52, 53)

Assim, a participação efetiva das mulheres no estudo demonstrou o maior interesse em compartilhar e divulgar suas ideias, opiniões e posicionamento junto à pesquisa, se comparado ao sexo masculino. 
Gráfico 2 - Questão 3 do formulário: Faixa Etária (idade)

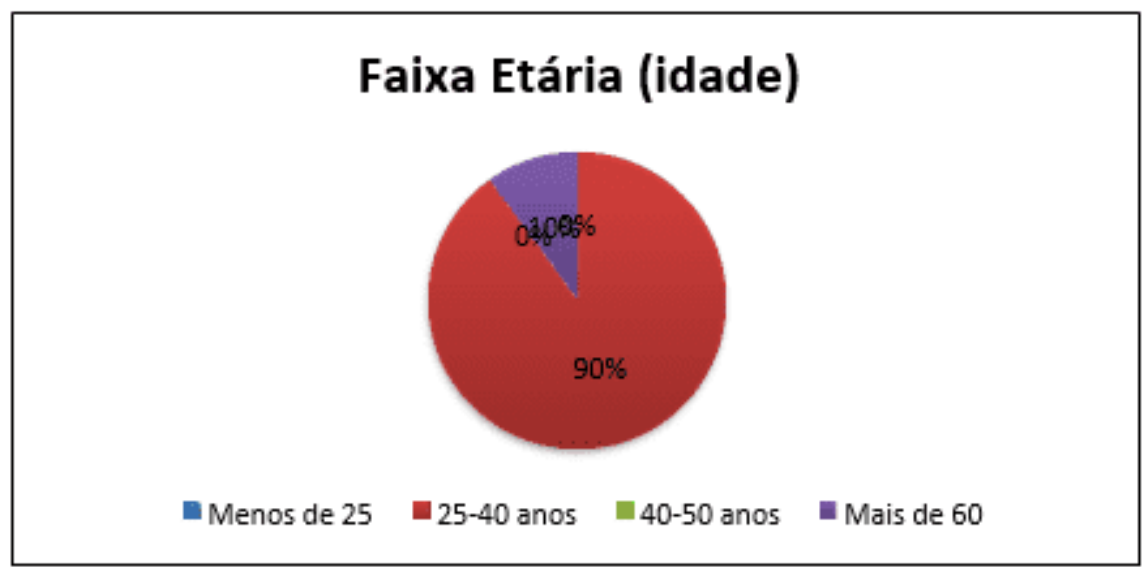

Fonte: Própria autora (2018)

De acordo com o gráfico acima, vemos que a predominância de participantes foram com idade entre 25 e 40 anos. Ou seja, podemos notar uma maior participação de um público mais jovem antenado no meio digital, pois as pessoas mais jovens "reagem mais rápido às transformações que estão ocorrendo no mundo, como a globalização e os avanços tecnológicos. [...] Na verdade, estão entre os principais propulsores da mudança no mundo." (Idem, p. 51). Essa população é apontada como a mais participativa e engajada em meio as redes sociais da empresa. Assim, podemos considerar que o público jovem está cada vez mais interessado em buscar informações e possibilidades que o mercado imobiliário em questão oferece.

\subsection{PARTICIPAÇÃO DOS CLIENTES NAS REDES SOCIAIS}

Com referência ao tempo, os participantes das redes sociais da empresa sujeitos deste estudo se situaram em: $50 \%$ dos usuários são seguidores das redes no período de 1 a 2 anos; considerando que a Prime Residencial vem investindo no marketing digital em meio as redes sociais nesta mesma temporalidade; $20 \%$ dos participantes corresponderam a menos de 1 ano e, assim como, os que se são seguidores em torno de 3 a 5 anos. Estes últimos se caracterizam como clientes já existentes da empresa, mesmo antes das redes sociais; e apenas $10 \%$ dos participantes são seguidores mas não clientes. Ou seja, estes, ainda que não sejam clientes, expressam interesse nos 
produtos e serviços oferecidos pela empresa, visto que seguem os perfis nas redes sociais.

Os sujeitos pesquisados informaram que conheceram a empresa Prime Residencial por meio das seguintes mídias: 50\% apontaram o Instagram como contato inicial; $40 \%$ por meio de mídias off-line (contato com corretores, visita ao stand de vendas, amigos, familiares, anúncios impressos, etc); e 10\% desses sujeitos passaram a conhecer a empresa por meio do Facebook. Como podemos notar, as estratégias de marketing on-line e off-line acabam se complementando. Ou seja, há uma convergência tecnológica que reúne tanto o digital quanto o tradicional no envolvimento de pessoas e grupos como consumidores no mercado empresarial enquanto sujeitos ou seres humanos plenos de interesses, de valores e direitos.

\subsection{REGISTROS DE SATISFAÇÃO DOS USUÁRIOS}

Quanto a satisfação, $80 \%$ dos usuários consideraram o serviço em meio as redes sociais da empresa satisfatório. Apreensão confirmada pela questão referente a classificação do atendimento e retorno das informações pontuada como: 20\% excelente, $60 \%$ bom e $20 \%$ péssimo. O que demonstra a funcionalidade das redes sociais como canal de divulgação e engajamento com o público seguidor.

\subsection{POSIÇÕES E SUGESTÕES DOS USUÁRIOS}

Não clientes: $20 \%$ sugerem que a empresa deveria utilizar outros tipos de divulgação para além das redes sociais, embora que não tenham mencionado quais estratégias de marketing; $10 \%$ solicitaram maiores informações sobre a empresa e seus empreendimentos com disponibilidade de mais fotos reais e atualizadas; e outros $10 \%$ registraram que o serviço de comunicação nas redes sociais é excelente.

Clientes: Representaram 60\% dos usuários participantes da pesquisa e se posicionaram de maneira mais incisiva e avaliativa com relação as redes sociais (online) e a respeito dos contatos pessoais (off-line) consumidor-empresa. Os clientes 
solicitaram um maior feedback por meio das redes sociais, que fosse disponibilizado maiores informações por meio de imagens e vídeos para acompanhamento das obras.

Com relação as redes sociais, as informações fornecidas "são uma e quando chega na hora da compra é outra, ainda mais no processo com as papeladas." (Usuário A). Considerando que o processo de vendas e suas estratégias nas redes sociais foram consideradas boas, o serviço fornecido após a venda (pós-compra) não foi satisfatório, pois "Na hora de vender é uma maravilha, mas depois que compra o imóvel a empresa esquece os clientes. Acho que deveríamos ser igualmente tratados tanto das redes sociais quanto pessoalmente" (Idem). Posicionamento reafirmado por outro consumidor: "Nas redes sociais o feedback é sempre bom, mas pessoalmente ou por telefone sempre deixa a desejar." (Usuário B)

Tais posicionamentos e sugestões dadas pelos usuários por meio desta pesquisa, nos revelaram características do novo consumidor, que não se enquadram como passivos, mas como sujeitos ativos em relação às estratégias de comunicação de marketing. $A$ percepção que o consumidor tem da empresa é uma junção de visões e troca de experiências tanto on-line (redes sociais) quanto off-line (contato pessoa a pessoa). Assim, concordamos com Kotler (2017, p. 39) que "tudo indica que os mundos on-line e off-line acabarão coexistindo e convergindo.". No mundo globalizado de hoje, a grande imersão de novas tecnologias e plataformas sociais afeta o meio social, não apenas no espaço digital, mas também no espaço físico pessoal; o que não significa que a interação digital seja totalmente suficiente, como notamos mediante as analises de posicionamento dos usuários na pesquisa em questão.

A fala e/ou escritos produzidos pelos usuários emitiram discursos concretos sobre uma realidade concreta, no sentido de que produzem efeitos, sentidos entre sujeitos interlocutores e apontaram revisões para sanar possíveis conflitos e reafirmar a aliança entre os sujeitos empresa-consumidor. 


\section{CONSIDERAÇÕES FINAIS}

$\mathrm{O}$ artigo em tela possibilitou apreendermos alguns aspectos e posicionamentos sinalizados pelos registros dos usuários das redes sociais da empresa Prime Residencial, foco deste estudo, que responderam aos objetivos geral e específicos propostos por esta pesquisa.

Inicialmente, consideramos que a utilização das redes sociais como estratégia digital de marketing on-line cumprem o papel facilitador de divulgação de informações da empresa/marca e seus produtos. As redes sociais são canais de comunicação e interação entre a empresa e os usuários, sendo considerado pelos próprios participantes como satisfatória.

Embora tenham sido registradas sugestões quanto à ampliação e diversificação de outras mídias de divulgação sobre a empresa e seus produtos, de maneira enfática a atualização de fotos e vídeos que retratassem de maneira real os processos de acompanhamento das obras em construção.

O público do sexo feminino e o público mais jovem foram os grupos que tiveram maior engajamento quanto a participação no formulário, o que nos levou a apreender que o sexo feminino se localizou numa faixa etária entre 25 a 40 anos, confirmando-se como segmento mais atento e receptivo às informações nas redes sociais segundo seus interesses pessoais, familiares tornando-se sujeito influenciador.

Outra consideração refere-se à queixa principal dos usuários clientes com relação a comunicação pessoal (off-line) com a empresa no processo do pós-compra. Ou seja, enfatizaram que os atendimentos pessoais (pessoa a pessoa) se diferem do atendimento por meio das redes sociais (on-line) e apontaram a falta de um acolhimento maior por parte dos funcionários da empresa, assim como a ausência de uma orientação adequada com relação a documentações e processos contratuais dos empreendimentos. Um ponto a ser revisto e reavaliado, considerando que o cliente é o elemento fundamental no processo de divulgação de imagem e de produtos e serviços oferecidos pela empresa. 
Acreditamos que o papel do Marketing 4.0 em meio às relações de comunicação com o cliente é essencial para que exista uma ligação maior entre empresa-consumidor no âmbito on-line e off-line. Ou seja, para que os processos de diálogo entre ambos os lados seja eficaz, deve haver uma convergência maior entre as mídias de comunicação e estratégias utilizadas para se captar o interesse e conquistar o cliente não apenas de forma empresa- consumidor, mas trabalhar a relação de parceria entre ambos, e, acima de tudo, na utilização das redes sociais para solução de problemas existentes; tanto na comunicação quanto relação pessoa a pessoa.

\section{REFERÊNCIAS}

BAUMAN, Zygmunt. O mal-estar da pós-modernidade. Rio de Janeiro: Zahar, 1998.

CAUNE, Jean. Cultura e Comunicação: Convergências Teóricas e Lugares de Mediação. 1. ed. São Paulo: Editora Unesp, 2014.

FIGARO, Roseli et al. Comunicação e Análise do Discurso. 1. ed., 2ª reimpressão. São Paulo: Contexto, 2015.

KOJÈVE, Alexandre. Introdução à leitura de Hegel. Rio de Janeiro: Contraponto, 2002.

KOTLER, Philip. O Marketing sem segredos. Porto Alegre: Bookman, 2005.

KOTLER, P; KARTAJAYA, H; SETIAWAN, I. Marketing 4.0: Do Tracicional ao Digital. Rio de Janeiro: Sextante, 2017.

MADEIRA, Carolina Gaspar; GALLUCCI, Laura. Mídias Sociais, Redes Sociais e sua Importância para as Empresas no Início do Século XXI. Apresentado no XXXII Congresso Brasileiro de Ciências da Comunicação - Curitiba, PR - 4 a 7 de setembro de 2009.

MARQUES, Danilo Araújo. No fio da navalha: historicidade, pós-modernidade e fim da história. Belo Horizonte: Editora UFMG, 2017. 
MESQUITA, Renato. O que é Marketing: tudo que você precisa saber sobre o assunto. Disponível em: < https://marketingdeconteudo.com/o-que-e-marketing/> Acesso em: 20 jul. 2018.

QUINTANILHA, Pedro. 0 que são mídias sociais? Disponível em: < https://pedroquintanilha.com.br/midias-sociais/o-que-sao-midias-sociais/> Acesso em: 20 jul. 2018.

REZ, Rafael. Marketing 4.0: do Tradicional ao Digital, passo a passo. Disponível em: < https://novaescolademarketing.com.br/marketing/marketing-4-0/> Acesso em: 20 jul. 2018. SETTON, Maria da Graça. Mídia e educação. 1. ed., 2ª reimpressão. São Paulo: Contexto, 2018.

THOMPSON, John B. A mídia e a modernidade. Uma teoria social da mídia. 15 ed. Rio de Janeiro: Vozes, 2014.

Enviado: Novembro, 2018.

Aprovado: Setembro, 2019. 